\title{
The Myth of Profit-Shifting Trade Policies
}

\author{
Onur A. Koska \\ Department of Economics, \\ Middle East Technical University, Ankara, Turkey \\ E-mail: koska@metu.edu.tr \\ Phone: + (90) 3122103046
}

\section{Frank Stähler}

Department of Economics, University of Tübingen, Tübingen, Germany and Department of Economics, University of Adelaide, Adelaide, Australia and Center for Economic Studies, The Ifo Institute (CESifo), Munich, Germany

E-mail: frank.staehler@uni-tuebingen.de 


\title{
The Myth of Profit-Shifting Trade Policies
}

\author{
Onur A. Koska* \\ Frank Stähler ${ }^{\dagger}$
}

December 2015

\begin{abstract}
Since Dixit (1984), it is well accepted that a home country's best policy is to ban imports in an oligopolistic market if the resulting monopoly has a cost advantage over imports. This note (i) provides a formal proof and (ii) extends this result to symmetric firms. When domestic instruments are available, the optimal policy in a non-cooperative game is to subsidize local production such that it completely replaces imports. This policy is also globally first-best.
\end{abstract}

Keywords: Import tariffs, export subsidies, profit shifting

JEL Classification: F13

${ }^{*}$ Corresponding Author: Middle East Technical University (METU), Department of Economics, Üniversiteler Mah. Dumlupinar Blv. No:1, 06800 Çankaya, Ankara/Turkey. Tel: +(90) 3122103046. Fax: +(90) 312210 7964. Email: koska@metu.edu.tr

${ }^{\dagger}$ University of Tübingen, University of Adelaide and CESifo, Department of Economics, Mohlstr. 36 (V4), D-72074 Tübingen, Germany, frank.staehler@uni-tuebingen.de 


\section{Introduction}

It seems to be a well-established result of international trade theory that export subsidies and/or import tariffs are used in an environment of imperfect competition to shift profits from a foreign firm to a domestic country $]^{1}$ This result, however, relies heavily on the assumption that other domestic policy instruments are not available, which is mostly overlooked in the literature (Bagwell and Staiger, 2012). In fact, both the import tariff and the export subsidy are relatively inefficient instruments compared to subsidizing production for the local market, and restricting the use of import tariffs and/or export subsidies will have no effect insofar as there is no restriction on domestic policy instruments. Dixit (1984) acknowledges this especially when local firms have a cost advantage over imports and compete in oligopolistic markets. In this note, we show in a simple international duopoly model that even without a cost advantage prior to any policy intervention, trade instruments do not play any role for optimal policies when domestic policy instruments are available. Furthermore, the globally first-best policy is an equilibrium in this non-cooperative game.

\section{The model}

Demand in each country is determined by a representative consumer's optimal behavior. We assume a quasi-linear utility function $U(Q, Z)=u(Q)+Z$ for the domestic consumer, where $Z$ is the numeraire good produced under perfect competition by the use of labor such that one unit of labor produces one unit of the numeraire good. $Q$ is the amount of good produced under imperfect competition. With the wage normalized to unity under these assumptions, demand is given by $u^{\prime}(Q)=p(Q)$. In our model, preferences need not be the same across countries, so foreign demand will be determined by $u^{* \prime}(Q)=p\left(Q^{*}\right)$; in what follows, all foreign activities are denoted by a star. The market for $Q$ and $Q^{*}$ is segmented and served by a domestic and a foreign firm. Consider the domestic country in which aggregate consumption is given by $Q=y+x^{*}$, where $y$ denotes domestic production for the domestic market and $x^{*}$ denotes foreign exports to the domestic country. As standard in Cournot duopoly models, we assume that both firms' outputs in a market are strategic substitutes in the sense of Bulow et al. (1985) such that

$$
p^{\prime}+p^{\prime \prime} y<0 ; \quad p^{\prime}+p^{\prime \prime} x^{*}<0 ; \quad p^{\prime}+p^{\prime \prime} y^{*}<0 ; \quad p^{\prime}+p^{\prime \prime} x<0,
$$

which guarantees that the reaction curves are downward sloping.

\footnotetext{
${ }^{1}$ See Brander (1995) for a review of the strategic trade policy literature.
} 
This is a two-stage game: in the first stage, each government sets its policy as to maximize national welfare; and in the second stage, each firm maximizes its profits across both countries. The domestic government may use three instruments: (i) a production subsidy for the local market $(s)$; (ii) an export subsidy $(\sigma)$; and (iii) an import tariff $(t)$. It should be clear that the production subsidy for the local market could easily be replaced by a domestic consumption subsidy. Furthermore, there is a per-unit trade cost of size $\tau \geq 0$, which makes exports at least as costly as serving the market by local production. If $s=\sigma$, the subsidy would not distinguish between the target markets of production. Similarly, the foreign government can employ the same set of instruments, denoted by $s^{*}, \sigma^{*}$ and $t^{*}$.

Without loss of generality, we normalize each firm's (constant) marginal production cost to zero. $2^{2}$ Consequently, domestic profits are given by

$$
\Pi=(p+s) y+\left(p^{*}+\sigma-t^{*}-\tau\right) x
$$

where $x$ denotes the domestic exports, and foreign profits are given by

$$
\Pi^{*}=\left(p^{*}+s^{*}\right) y^{*}+\left(p+\sigma^{*}-t-\tau\right) x^{*},
$$

where $y^{*}$ denotes foreign production for the foreign market. Profit maximization implies the first-order conditions:

$$
\begin{aligned}
\Pi_{y}=p^{\prime} y+p+s \leq 0 & (=0 \text { if } y>0), \\
\Pi_{x}=p^{* \prime} x+p^{*}+\sigma-t^{*}-\tau \leq 0 & (=0 \text { if } x>0), \\
\Pi_{y^{*}}^{*}=p^{* \prime} y^{*}+p^{*}+s^{*} \leq 0 & \left(=0 \text { if } y^{*}>0\right), \\
\Pi_{x^{*}}=p^{\prime} x^{*}+p+\sigma^{*}-t-\tau \leq 0 & \left(=0 \text { if } x^{*}>0\right) .
\end{aligned}
$$

These first-order conditions give us the behavior of both firms in both markets for a given set of policy instruments $3^{3}$ We now turn to the first stage in which each government maximizes its national welfare using all of its three policy instruments. Domestic welfare, denoted $W(s, \sigma, t)$, is comprised of domestic consumer surplus, the domestic firm's profits from both markets and the change in the domestic government's revenues. Similarly, foreign welfare, denoted $W^{*}\left(s^{*}, \sigma^{*}, t^{*}\right)$, is comprised of foreign consumer surplus, the foreign firm's profits from both markets and the change in the foreign government's

\footnotetext{
${ }^{2}$ As cost advantages cannot be defined independent of output levels in the case of increasing marginal costs, we confine the analysis to constant marginal costs.

${ }^{3}$ Furthermore, as is the standard assumption in the literature, we assume that the effect of the own output on own marginal profits is stronger than on the rival's marginal profits: $\Pi_{y y} \Pi_{x^{*} x^{*}}-\Pi_{y x^{*}} \Pi_{x^{*} y}>0$ and $\Pi_{y^{*} y^{*}} \Pi_{x x}-\Pi_{y^{*} x} \Pi_{x y^{*}}>0$. This guarantees a positive value of the determinant of the Jacobian matrix. Also we assume second-order sufficiency in the maximization problem (see the Appendix).
} 
revenues. We are now ready to present our main result. The appendix has all the details, including the formal proof of our main result.

Proposition 1 If the welfare functions $W(s, \sigma, t)$ and $W^{*}\left(s^{*}, \sigma^{*}, t^{*}\right)$ are quasi-concave, an equilibrium exists in which

- neither country will use import tariffs and/or export subsidies,

- both countries will employ a subsidy for production for the local market such that the domestic price is equal to the domestic marginal production cost, and as a result

- there will be no trade.

Note carefully that this is a non-cooperative equilibrium which implies the optimal, firstbest outcome. In equilibrium, neither import tariffs nor export subsidies are used to shift profits. The intuition for this result is as follows. An import tariff would shift the foreign firm's profits to some extent to the domestic government, but at the same time it would create a negative externality for domestic consumers, as aggregate output would decline and prices would increase. An export subsidy would shift the foreign firm's profits to the domestic firm, as the domestic firm would produce more aggressively in the foreign market. At the same time, however, it would create a positive externality for foreign consumers who would enjoy a larger aggregate supply and lower prices. So, an import tariff would create a negative externality for domestic consumers and an export subsidy would create a positive externality for non-domestic consumers only. Subsidizing production for the local market has none of these unwarranted externality effects and is, thus, a much more efficient instrument. As trade policy instruments will not be used in equilibrium, the following result is obvious.

Proposition 2 Restricting the use of import tariffs and/or export subsidies has no effect as long as a production subsidy for the local market is not restricted.

\section{Concluding remarks}

In this note, we provide a formal proof that shows in a simple international duopoly model that trade instruments do not play any role for optimal policies when domestic policy instruments are available and firms have identical constant marginal cost of production. However, this note does not intend to promote the use of a specific policy, as their use may incur other problems beyond the scope of our model; see, for instance, Maggi (1999) 
for the case of asymmetric information. On the contrary, it shall be duly noted that for the sake of completeness and correctness, discussions of the availability of different policy instruments are highly warranted in studies on the strategic trade policy in imperfectly competitive markets.

\section{Appendix}

\section{Proof of Proposition 1}

Let us consider the domestic market (similar expressions will hold for the foreign market) and assume that interior solutions exist which may include bounds. Differentiating (2) yields $\Pi_{y y}=2 p^{\prime}+p^{\prime \prime} y<0, \Pi_{y x^{*}}=p^{\prime}+p^{\prime \prime} y<0, \Pi_{x^{*} x^{*}}^{*}=2 p^{\prime}+p^{\prime \prime} x^{*}<0, \Pi_{x^{*} y}=$ $p^{\prime}+p^{\prime \prime} x^{*}<0, \Pi_{y s}=\Pi_{x^{*} \sigma^{*}}^{*}=1$ and $\Pi_{x^{*} t}^{*}=-1$ while all other second derivatives are zero. Total differentiation yields

$$
\underbrace{\left[\begin{array}{cc}
2 p^{\prime}+p^{\prime \prime} y & p^{\prime}+p^{\prime \prime} y \\
p^{\prime}+p^{\prime \prime} x^{*} & 2 p^{\prime}+p^{\prime \prime} x^{*}
\end{array}\right]}_{\equiv J}\left[\begin{array}{c}
d y \\
d x^{*}
\end{array}\right]=\left[\begin{array}{c}
-1 \\
0
\end{array}\right] d s+\left[\begin{array}{c}
0 \\
-1
\end{array}\right] d \sigma^{*}+\left[\begin{array}{l}
0 \\
1
\end{array}\right] d t
$$

where the Jacobian determinant $\operatorname{det}(J)=p^{\prime}\left(3 p^{\prime}+p^{\prime \prime}\left(y+x^{*}\right)\right)>0$. We can now determine the partial changes in the optimal outputs $y, x^{*}$ and $Q=y+x^{*}$ :

$$
\begin{gathered}
y_{s}=-\frac{2 p^{\prime}+p^{\prime \prime} x^{*}}{\operatorname{det}(J)}>0, \quad x_{s}^{*}=\frac{p^{\prime}+p^{\prime \prime} x^{*}}{\operatorname{det}(J)}<0, \quad Q_{s}=-\frac{p^{\prime}}{\operatorname{det}(J)}>0, \\
y_{\sigma^{*}}=\frac{p^{\prime}+p^{\prime \prime} y}{\operatorname{det}(J)}<0, \quad x_{\sigma^{*}}^{*}=-\frac{2 p^{\prime}+p^{\prime \prime} y}{\operatorname{det}(J)}>0, \quad Q_{\sigma^{*}}=-\frac{p^{\prime}}{\operatorname{det}(J)}>0, \\
y_{t}=-\frac{p^{\prime}+p^{\prime \prime} y}{\operatorname{det}(J)}>0, \quad x_{t}^{*}=\frac{2 p^{\prime}+p^{\prime \prime} y}{\operatorname{det}(J)}<0, \quad Q_{t}=-\frac{p^{\prime}}{\operatorname{det}(J)}<0 .
\end{gathered}
$$

Similar expressions hold for $y^{*}, x^{*}$ and $Q^{*}$ which we do not report here. We now write domestic welfare as a function of all domestic policy instruments:

$$
W(s, t, \sigma)=u(Q)-p(Q) Q-p^{\prime}(Q) y^{2}-p^{* \prime}\left(Q^{*}\right) x^{2}+t x^{*}-s y-\sigma x .
$$

The first two terms are the consumer surplus, the third and the fourth terms are the domestic firm's maximized profits respectively from the domestic market and the foreign market, and the last three terms collect the effect on governmental revenues. The marginal welfare changes, using $u^{\prime}(Q)=p(Q)$, are given by

$$
\begin{aligned}
W_{s} & =-p^{\prime} Q Q_{s}-Q_{s} p^{\prime \prime} y^{2}-2 p^{\prime} y y_{s}+t x_{s}^{*}-y-s y_{s}, \\
W_{t} & =-p^{\prime} Q Q_{t}-Q_{t} p^{\prime \prime} y^{2}-2 p^{\prime} y y_{t}+x^{*}+t x_{t}^{*}-s y_{t}, \\
W_{\sigma} & =-Q_{\sigma}^{*} p^{* \prime \prime} x^{2}-2 p^{* \prime} x x_{\sigma}-x-\sigma x_{\sigma} .
\end{aligned}
$$


We now demonstrate that our candidate equilibrium implies $W_{s}=W_{t}=W_{\sigma}=0$. The candidate equilibrium specifies that

$$
\begin{gathered}
x^{*}=0, \quad p^{\prime} y+s=0 \quad \Leftrightarrow \quad s=-p^{\prime} y, \quad Q=y, \\
\sigma=t=0, \\
x=0, \quad p^{* \prime} y^{*}+s^{*}=0 \quad \Leftrightarrow \quad s^{*}=-p^{* \prime} y^{*}, \quad Q^{*}=y^{*}, \\
\sigma^{*}=t^{*}=0 .
\end{gathered}
$$

Let us now check for domestic welfare; similar results hold for foreign welfare. The candidate equilibrium A.1 immediately implies $W_{\sigma}=0$. Furthermore,

$$
W_{s}=-y Q_{s}\left(p^{\prime}+p^{\prime \prime} y\right)-p^{\prime} y y_{s}-y, \quad W_{t}=-y Q_{t}\left(p^{\prime}+p^{\prime \prime} y\right)-p^{\prime} y y_{t},
$$

or equivalently

$$
\frac{W_{s}}{y}=-Q_{s}\left(p^{\prime}+p^{\prime \prime} y\right)-p^{\prime} y_{s}-1, \quad \frac{W_{t}}{y}=-Q_{t}\left(p^{\prime}+p^{\prime \prime} y\right)-p^{\prime} y_{t}
$$

Substituting in

$$
Q_{s}=-Q_{t}=-\frac{p^{\prime}}{\operatorname{det}(J)}, \quad y_{s}=-\frac{2 p^{\prime}}{\operatorname{det}(J)}\left(\text { because } x^{*}=0\right), \quad y_{t}=-\frac{p^{\prime}+p^{\prime \prime} y}{\operatorname{det}(J)}
$$

and multiplying $W_{s} / y$ and $W_{t} / y$ by $\operatorname{det}(J)=p^{\prime}\left(3 p^{\prime}+p^{\prime \prime} y\right)$ leads to

$$
\begin{aligned}
& \frac{W_{s} \operatorname{det}(J)}{y}=p^{\prime}\left(p^{\prime}+p^{\prime \prime} y\right)+2\left(p^{\prime}\right)^{2}-p^{\prime}\left(3 p^{\prime}+p^{\prime \prime} y\right)=0, \\
& \frac{W_{t} \operatorname{det}(J)}{y}=-p^{\prime}\left(p^{\prime}+p^{\prime \prime} y\right)+p^{\prime}\left(p^{\prime}+p^{\prime \prime} y\right)=0 .
\end{aligned}
$$

\section{References}

[1] Bagwell, K., R.W. Staiger (2012). Profit shifting and trade agreements in imperfectly competitive markets. International Economic Review 53: 1067-1104.

[2] Brander J.A. (1995). Strategic trade policy. In G. Grossman and K. Rogoff (eds), Handbook of International Economics, Volume III, Amsterdam: North Holland, pp. 1395-1455.

[3] Bulow, J., J. Geanakoplos and P. Klemperer (1985). Multimarket oligopoly: strategic substitutes and complements. Journal of Political Economy 93: 488-511.

[4] Dixit, A. (1984). International trade policy for oligopolistic industries. Economic Journal 94 (supplement): 1-16.

[5] Maggi, G. (1999). Strategic trade policy under incomplete information. International Economic Review 40: 571-594. 